\title{
Design-Based of FBFRP-Technique in Writing Computerized English Essays in the Light of CTL Method
}

\author{
Dedi Turmudi ${ }^{1}$ \\ \{tdeditur@gmail.com $\left.{ }^{1}\right\}$ \\ English Department of FKIP Universitas Muhammadiyah Metro Indonesia ${ }^{1}$
}

\begin{abstract}
Students and test takers of iBT faced difficult problem in solving how to write a full English Essay of different genres in 30 minutes with minimum 250 words. The designed technique facilitates students and test-takers how to write such essay in 30 minutes, but the result meets the standard ideal iBT TOEFL test model. The technique is called Forward-Back Forward Revising and Publishing (FBFRP) Technique. The designed is under the learning principles of CTL: critical creative and self-regulative thought. This study is 1) to provide a technique that can help students and test takers to develop their computerized-based English Essay effectively in 30 minutes, 2) to describe how the procedure of FBFRP technique work in writing computerized -based English Essay, 3) to shows readers how FBFRP technique was developed and validated. This is a research and development adopted by Borg and Gale (2003), Formative Evaluation taken by Tesmer (2013) self- evaluation, expert review, one- to-one, small group, and field test. The outcomes are 1) a technique that can help students and test takers called "FBFRP Technique, 2) a description or underlying principles of how FBFRP technique work in writing computerized-based English Essay, 3) the process of how FBFRP technique was validated. The product is applicable across disciplines in ELT or ESL context as an instructional tool, particularly for Academic writing course, and real test of internet-based TOEFL test takers.
\end{abstract}

Keywords: English, computerized essay, CTL; FBFRP technique; iBT TOEFL

\section{Introduction}

It has been a need to contribute a systemic solution to the problems of writing computerized-based essay faced by test takers of iBT TOEFL, and teaching purposes. The recent issues in writing skill reported that writing skill or ability was still a subject to concern. Many of Indonesian test-takers in the iBT TOEFL achieved insufficient score to meet the standard requirement [1]. This also happened to the students enrolled at Essay Writing course [2] where the researcher taught.

Reports showed that the problems faced were respectively from the highest to lowest one; mechanics, grammar, content, organization, and vocabulary [3]. Beyond writing types, the essays' scores of the Indonesian were average. Scholar reported the students' writing performance on TOEFL iBT and in required university writing courses [4, p. 20]. They claimed that there was correlation among whole dimension of the quality of academic writing tasks and academic writing course. 
Prior to this study was also reported by the scholars in different focus. Under the concern of the trends of designing e-learning and synchronous learning [5][6], the researcher dared to create this technique as a solution. This study is to contribute a research that examines correspondences between tasks in high-stakes assessments and the TLU domain. The study focuses on two stakeholder groups that are affected by test uses: students and instructors [7, p. 97].

In a broader coverage, English Testing Service (ETS) [1, p. 22] reported that the average scores of the Indonesian test-takers among countries was 21 of 30 iBT scores for both computerized integrated writing and independent writing task written in 55 minutes in total. Similar report showed that the average score was 22 of 30 maximum scores [4][8]. Other reports of essay' scores of iBT had a commonsense that the scores of essays remained problems [9], [10] and the average was in high-intermediate (17-23 of 30), including Indonesian's test-takers of iBT [1].

A similar study was conducted in Korea [11], nevertheless the focus was on the degree and types of difficulties, correlation, and perception by both test-takers and teachers. In addition, some scholars recently focused on developing other skills and assessment rather than writing production. Sathya (2013) reported the result of his study "Developing an E-Content Module on the poem [12]. Foley reported her study on the four skills; "Developing Academic Writing", whereas Wullur [13] reported their R and D in the productive skills: "Developing an English Performance Test" [13]. All of these studies have left great potential gaps for the current study. Therefore, the discrepancy must be answered. Lastly, this research is a follow of inquiry of the prior scientific research [14]-[16]. This is why he had created a technique to overcome those reported problems.

In brief, this study focused on developing a certain technique in enhancing the students' achievement in computerized English essay writing [16, p. 23].” So, this study is also under the lesson learned from empirical studies comparing handwriting and keyboard writing [17] henceforth, the study emphases on three aspects.

1. To provide a technique that can help undergraduate students and test takers of iBT develop their computerized-based English Essay effectively in 30 minutes.

2. To describe how the procedure or underlying principles of FBFRP technique works in writing computerized -based English Essay based on CTL principles.

3. To shows readers how FBFRP technique was developed and validated.

The final outcomes:

1. A technique that can help students and test takers of iBT called "FBFRP Technique write two types of essays effectively.

2. Descriptions or underlying principles of how FBFRP technique helps students and test takers of iBT in writing computerized -based English Essay based on CTL principles.

3. Reported the process of how FBFRP technique was validated by the model of Tessmer (2013).

The reason why a technique is created is various. He believes that this technique may promote good impact on the learners' achievement in context of education and the test takers in the context of a real test. Scholars reported that 'Self-Regulated Strategy Development (SRSD) and Automated Writing Evaluation (AWE)" were found to be effectively helping the learners [18]. This study also provides initial evidence that, as part of a program of writing instruction, AWE is associated with increased writing quality compared to writing instruction alone [18, $\mathrm{p}$. 266]. For that reason, a variant technique is proposed to use.

To end this, the proposed technique is called "Forward Back Forward Revising and Publishing Technique (FBFRP)." It emerges the wished condition in which the best essay results 
in a test has to meet an ideal criterion of an essay component; "format, grammar, vocabulary range, structure of the essay, punctuation, unity and coherence" [19, p. 18]. Lasty the creation of this technique is also under a consideration of digital and age and the impact on learning [20]. Accordingly, he is convinced this technique can make both undergraduate students and iBTTOEFL test-takers cover all the required criteria in the curriculum and iBT framework score criteria.

Above all, the outcomes reveal contribution to the science and technology by creating this technique and be used the Indonesian undergraduate students and iBT test takers in particular and for the entire globe.

\subsection{Technique in Teaching}

As a non-native speaker (NNS) of English, the researcher was often confused with the use of these terms: method, technique, and approach. For that reason, he clarified the proposed term by referring to some sources [21]-[23].

In his view, what is meant by an approach method in this context is what is proposed by [23] saying" a set of assumptions dealing with the nature of language, learning and teaching," whereas method is "an overall plan for a systematic presentation of a language based upon a selected approach" and a technique is "a specific activity manifested in the classroom that were consistent with a method and therefore were in harmony with an approach as well" [23, p. 14]. To make it clear, he meant FBFRP technique as a technique.

Since the term is clear, he had better discuss the criteria of a good teacher than debating endless points in the perspective of NNS. Accordingly, he summarized some good criteria of a teacher outlined by Harmer [24]-[26]. They have to have at least the following criteria: "attractive, create interesting materials, has broad knowledge out of his expertise, correcting without blaming, help his students rather than mock them (p.1-2.). The embodiment of the criteria is referred to an approach, method, and technique.

The researcher believes that his actions to develop a certain technique refers to a method called Contextual Teaching Learning (CTL) as proposed by scholars [27]-[29]. It is bounded to the three definitions: approach, method, and technique [23]. Consequently, the method in this context is not the one perceived by the Indonesians scholars as a technique, but a technique proposed by a native speaker of English or at least what Brown quoted. It has also similar meaning as proposed by some scholars. It is equivalent with strategies or tactics [30, p. 115]. Crediting them he is certain that their terms was a technique in English instructional.

Upon all, a technique in this context is a specification of this research so that the result will be met with the Brown's argument. That is why he insisted on developing a technique not a method because a technique is specific and more visible in the teaching process while method is broader and philosophical. When creating a method, some thoughts have to consider. They cover belief, assumption, and approach; learning theories such as naturalism, behaviorism, or nativism; psychological theory; and what materials for the developing technique. While a method is more theoretical rather than practical. That is why the researcher insisted that the created prototype was a technique or a procedure but not a method.

Referring to the five considerations, he is interested to develop a technique due to several reasons; it is more procedural, more applicable, and more practical, more logical, and specific. These reasons have led him to do research in the area of research and development believing this technique can answer or be a solution for the test takers. It is also believed to help other users in specific and for the students at university level in general. 


\subsection{The principles of Contextual Teaching Learning in Instructional Process}

Teaching essay writing may use many other techniques under the principles of a method or a technique; one of them is with Contextual Teaching Learning [27], [31]. Contextual Teaching Leaning (CTL) has specific characteristic of philosophy pertaining to the English essay writing. The philosophy covers meaningful connection, self-regulated learning, and collaborating, critical and creative thinking, reaching high standards of learning process. Of all principles above each of which was projected to have a specific role based on the four stages of FBFRP Technique.

Meaningful connections [32] were projected to use in the stage forward in which all the composed sentences had to be meaningful and inter-connected because its single sentence would be the reference for the entire supporting details.

Self-regulated learning [33] [34] was projected to master the graded steps in writing essay as a whole organized in FBFRP technique. This means that in every stage the learners monitor their development of writing essay based on the whole process of FBFRP without any help from outsiders such as teacher, mentor, or lecturer especially when they are taking the real test of computerized test.

Research in this field has reported that a self-regulated learning is positive [35]-[37]. The study on Self-Regulated Strategy Development (SRSD) with an Automated Writing Evaluation (AWE) system can be effective in teaching students argumentative writing [18, p. 266]. This is a confirmation that a technique is an adhesive aspect in every teaching process.

The next step is "collaborating" [38] it is projected to use in the stage of revising. In this sense, the learners can do what is so called "peer revision,' and 'teacher revision after a selfrevision process." However, this stage was limited to the situation where the learners were learning or doing an assignment. In the real test of computerized essay test, both of peer and teacher revision are omitted. Research in collaboration has shown a great influence of the learners' achievement [38][39].

Then, it is to have "critical and creative thinking." Being critical and creative thinker means to have such kind of behaviors such as expansive, innovative, inventive, unconstrained thinking while creative thinker means to have such kind of mental mode such as focused, disciplined, logical, constrained thinking [40, p. 1]. Both of these have bivariate relationship [41]. Both of these features of CTL were hoped to use in the second step of forward which is in the third step of whole FBFRP. Research in how important of CTL to teaching writing has been numerously report [27].

In this context both are meant to use in composing the supporting details. Composing them, in fact, needs a critical and creative thinking [42]. As the result, composing supporting details will enhance the high standard of a good English essay products or at least successful writing proficiency [43]. Thus, the whole of this technique was hoped to meet the high standards of the students' final work.

Lastly, to wrap those principles, the researcher embedded effective, accurate and comprehensive as the thread read in writing essay. Effective means using the given time maximum, accurate means ingenious in choosing diction and syntax, while comprehensive means all the related things are covered effectively. So, the three principles are the spirits of the adopted CTL principles in the current study. 


\subsection{Teaching Technique and Writing Essay at Universities}

Essay writing teaching techniques implemented by any teacher-educator authors (TEAs) including his personal experiences both as a graduate student and a lecturer. However, he found poor choice of techniques with which the taught students could produce sufficient English essay products. He faced a limited number of techniques such as free-technique, scaffolding technique, three steps technique or even with other conventional technique.

Those implemented techniques; however, did not make and meet the ideal criteria for students to get average score 70 of 100 scale and $90 \%$ of the essay test-takers passed successfully [2]. Accordingly, he believed and argued that those implemented techniques did not meet Brown's criteria namely "brainstorming, working in group, free writing, and the drafting and revising [23, pp. 348-350].

In composing the writing instructional, he referred to an essay process recommended by Brown et al with the following principles: (1) incorporating practices of "good" writers, (2) balancing process and product, (3) accounting for cultural and literary backgrounds, (4) connecting reading and writing, (5) providing as much authentic writing, and (6) being you are your technique in terms of prewriting, drafting, and revising stages [23, pp. 348-350]. All of these bases are counted in a hope of providing a better product of essay writing.

Unlike the FBFRP Technique, a scholar suggested the six- step guide to writing as summarized in the following points; getting ideas, choosing or selecting the ideas, outlining, drafting, revising, and editing [44, p. vii]. These tips are assumed to be the whole process of how to get success in writing essay. On the contrary, the researcher steps in a further phase are unlike the Greenville but how to develop the clear idea into a good writing piece. Thus, the recommended steps by Grenville are in the different stage of writing although to some extent it is alike.

Other scholar formulates the writing process into several phases; "pre-writing, drafting, self-revising, peer adult revising, editing, and publishing" [45, p. 42]. The processes seem to be comparable with that of the researcher's formula. Both promote revising and publishing although they are set for different process and purpose. Thus, both Grenville and Sundem mean the different things laid in the same terms with the authors.

\subsection{Essay Materials at Higher Education}

The increasing studies on investigating the essay product has been reported in many journal articles. Some studies applied Toulmin Element to investigate coherence [46][47]. Another study focused on timed argumentative essay [2][48]. Some others reported the essay based on moves [49]. All the empirical works focused on various aspects.

Essay writing in the context of the researcher was a main course for students who were at seven semester and was a part of required elective course. This course was also a common subject at English Department although the name of the course might be different. This course was further a perpetuation of writing 1 , to writing 4 [16].

As a part of academic writing, it requires certain skills. Hogue proposes that these skills include "sentence structures or how to arrange words in a sentence, an organization or how to arrange ideas in a paragraph, and, of course, grammar and punctuation [50, p. 2]. Thus, writing essay has to be well prepared and programmed so that it can result a good outcome of an essay writing product [51]. A good essay has accurate sentences or good grammatical structures. The accuracy is absolutely needed because an essay quality is determined by its level of accuracy [52][53]. 
The proposed competences for the students are able to 1).express any idea in a written text with various diction and correct grammatical aspects, 2).develop any different text with different genres such as descriptive, opinion, argumentative, discussion, cause and effect, comparison and contrast, process or procedure hortatory, expository and report essay, 3).put the skills of essay in the context of academic writing and scientific research through a set of process of paraphrasing, summarizing, and note-taking [54].

The objectives of this course were to provide the enrolled students with the following outcomes. They were hoped to 1). Master the skill of writing essay at advance level, 2).develop all required genres ended with a portfolio, 3).finish their undergraduate thesis or what is locally called "script" as their culmination process of study. In other words, an essay course was aimed at enhancing the students with high Language proficiency for writing [30]. Whereas the availability of the technique was to make the learners play a clear role in 'interactional activities, learner-centered method, learning centered methods, not in "teacher-centered methods [55].

\subsection{The Result of Essay Instructional at Higher Education}

The result of teaching essay process referred to the score gained by the students after taking essay course taught in conventional techniques. Looking back to the documents in the researcher context, until the 5 passed years, the result was still in average level or equivalent with satisfactory in the qualitative grades. However, due to limited researcher in Essay study, the research findings of the same interest are not considered.

To make the expected outputs of this study, some research questions are set up. Thus, the research is called Developing FBFRP Technique in writing computerized English Essay or called "Forward Back Forward Revising and Publishing (FBFRP) technique."

1. What is the form of a technique that can help test takers or essay writers develop their ability to write an essay in short, limited time?

2. How does the procedure or underlying principles of FBFRP technique work in boosting the test takers of computerized English essay?

3. How is the FBFRP technique validated by the Tesmer's Formative Evaluation?

\section{Method}

\subsection{Design}

The research design was research and development [56] with further technique through validation process of [57] called "Formative evaluation." It was used to validate the technique called Forward Back Forward Revising and Publishing (FBFRP) Technique. The process of product validation went through self- evaluation, expert review, one- to-one, small group, and field test. The small-scale field test was carried out and the large scale of field test would be after the publishing of this paper.

\subsection{Materials or Participants and Setting}

The self-evaluation was resulted from a survey and the result was arranged in form of some questionnaires and assigned in the method. This questionnaire was then spread over the enrolled 
students on the basis of Tessmer procedures. The instruments consisted of 10 questions with 3 aspects to rate on the basis of Likert Scale.

This research was carried out in English Department of Universitas Muhammadiyah Metro. 70 participants took part; 20 male and 50 female students of all semester enrolled in English essay writing course. They had different level of English proficiency and length of their study. However, they had a commonsense in that they were required to take writing course 1 to 4 and ended with essay writing.

\subsection{Data Collecting Technique}

The data was collected on the bases of formative evaluation by Tessmer [57]. This procedure was proceeded through the four staged steps below as described in Figure 1.

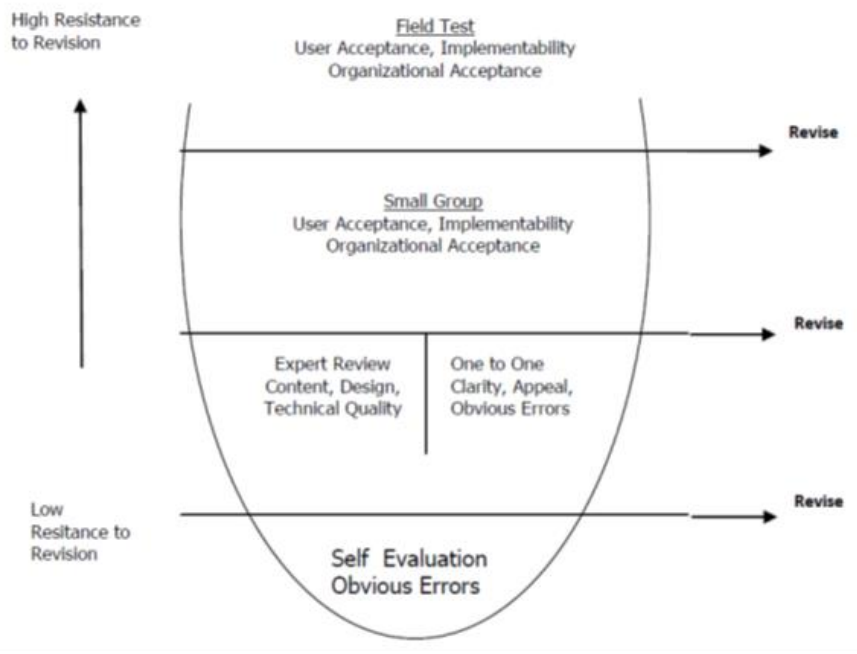

Fig 1. Flows and design of formative reseach.

\subsubsection{Expert Review and One to One Judgement}

The first prototype resulted from self-evaluation was submitted to an expert to get it reviewed. The process of expert review was represented by the expert in methodology Together with self-evaluation was a review sheet. The requested reviewer was told to judge accordingly qualitatively. The criteria were content, design, and technical quality. The expert was given to judge with certain scale from 0 to 100 scale. The result was called the first-prototype.

This first-prototype was then brought to two best students in essay writing to review the first-protype. This was one-to-one review. The researcher asked them separately to judge the first-prototype. The measurement consisted of clarity, appeals and obvious errors. There three scales were judged with certain quality from 0 to 100 scale. The result of this was called the first-prototype.

The result of this review together with review from expert were combined. He revised it considering the suggestions and notes from both expert reviewer and one to one reviewers and testers. Thus, the result is called first revised-protype one. It was then validated in the next step called small group. 


\subsubsection{Small Group}

The first revised protype-one was brought to small group. 26 students from were asked to review the first revised protype-one. 26 students were requested to judge. They were equipped with certain instruments of questionnaires. The aspects included in the instruments were user acceptance, implementability, and organizational acceptance.

User acceptance consists of 10 questions with Likert scale model while the implementability comprised of 10 questions with Guttman model design, and the organizational acceptance covered 10 questions with Guttman model design. They judged the first revised prototype-one, Further, he fixed the revised prototype-one and improved accordingly. Finally, the product is called revised protype-two. Hence, this later protype was brought to the next step called field test.

\subsubsection{Field Test}

The field test was done as an experiment to validate the revised protype-two. In this phase 27 students were assigned to read and review the revised prototype-two. They were enrolled at English Department. The aspects included in the instruments were user acceptance, implementability, and organizational acceptance.

User acceptance consists of 10 questions with Likert scale model while the Implementability comprised 10 questions with Guttman model design, and the organization acceptance covered 10 questions with Guttman model design. Collecting all of their reviews he then revised and improved the revised prototype-two. This phase resulted a good result called prototype-three. The goals were to harvest practical, effective, and efficient product. The result of this revision was called "final prototype".

\subsection{Data Analysis Technique}

The data analysis was carried through several steps. The process covered document analysis and document report. First, the researcher sorted the condition of the submitted answer sheets of questionnaire. He confined if all required fields were answered. Then, he began recapping and put the results on a specific table of recaps. In this stage, he plotted the quantitative recap and qualitative ones. Finally, he calculated to which category the data belong.

\subsubsection{Document Analysis}

The result of the Tessmer model was analyzed using criteria content analysis (CCA) under the model of expert [58]. This was applied to the result of experiment from the field. All were analyzed quantitatively and qualitatively categorized accordingly. All the results of this were used to the revise the revised prototype three and thus a final product was harvested. There was not any statistical calculation was created but descriptive statistics if needed. However, how the product is resulted is explained chronologically in the document report.

\subsubsection{Document Report}

This was a process when the researcher formulated all the gained data in the previous process in the form of report that was sent to, the ministry of Research and Technology and 
Higher Education of Indonesia, and an article to be presented and published in an international Conference and International Journal as an output of this research.

\section{Results and Discussion}

Since this study is trying to answer three research questions. The results of this research are a product called Forward Back Forward Revising and Publishing Technique or abbreviated to FBFRP Technique, Procedures and Learning Principles, and Validation process.

3.1 What is the form of a technique that can help test takers or essay writers develop their ability to write an essay in short, limited time?

Table 1 shows Procedures and Underlying Principles of FBFRP Technique.

Table. 1. Procedures and Underlying Principles of FBFRP Technique.

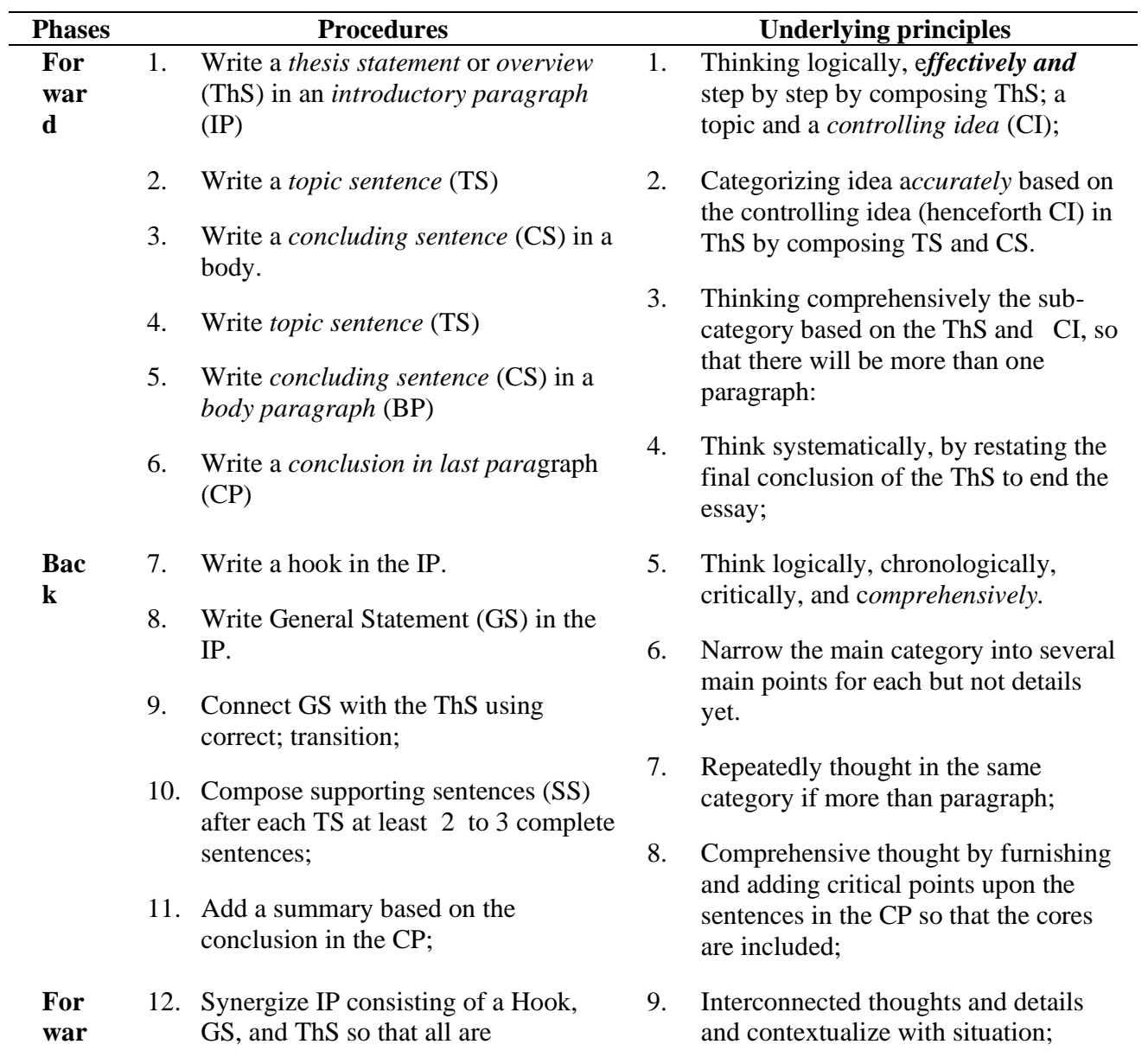


d

13. Compose supporting details (SD) in every SS, with 2 to $3 \mathrm{SD}$;

14. Add the $\mathrm{CP}$ with an additional sentence constituting the five features of CS; prediction, suggestion, recommendation, summary, and restatement;

Revi sing

Publ ishin g
15. Compose a good title which matches with the topic.

16. Revise the grammatical aspects, word choice, format, in the IP and rationalizing the flows (unity and coherence);

17. Revise the grammatical aspects, word choice, format, in the BP and rationalizing the flows (unity and coherence);

18. Revise the grammatical aspects, word choice, format, in the BP and rationalizing the flows (unity and coherence);

19. Submit the essay product to the lecturer or publish it in the target journal or website based on the plan;
10. Comprehensive thoughts and step by step thoughts; from main to category and lead to detail with real example;

11. Integrated thoughts put in the CP.

12. Unity and coherence thoughts;

13. Self-regulated on linguistics aspect;

14. Cooperative and self-correction (Self revision, Peer Revision, and Teacher Revision)

15. Open minded and open to feedback;

16. Think comprehensively and mastery learning leading to a portfolio

\subsection{How does the procedure of FBFRP technique work in boosting the test takers of computerized English essay?}

The procedures and underlying principles of FBFRP technique work in boosting the test takers of computerized English essay based on CTL applied in the iBT TOEFL essay test.

Reviewing the CTL method [59], this FBRP Technique is on the premise of constructivism in language pedagogy and language learning [60], and second language learning [61], and foreign language teaching [62]. For that reason, the researcher summarized the important points as the underlying principles for the FBFRP Technique?

This technique employs meaningful connection, self-regulated learning, collaborating, critical and creative thinking, reaching high standards of learning process, and accurate, effective, and comprehensive (AEC). Each of them has its own premise and scaffolds the process.

Meaningful connections are used in the stage of "forward" in which all composed sentences had to be meaningful and inter-connected. It is so because every single sentence will be a reference for the entire supporting sentences and details. Self-regulated learning is applied in 
the graded steps in writing essay as a whole organized in FBFRP technique. In this stage a test taker has to harvest the related supports and details for the existing sentences. Collaborating is used in the stage of "revising." The learners can do what is so called "peer revision,' and "teacher revision" after doing a self-revision process." However, this is only applicable in learning essay not in real test of iBT TOEFL. Critical and creative thinking are used in the whole process of composing the designated topic. When all principles are embedded, the result must be accurate, effective, and comprehensive (AEC). Test-takers are to have such kind of affection such as expansive, innovative, inventive, unconstrained thinking while creative thinker means to have such kind of mental mode such as focused, disciplined, logical, constrained thinking.

The underlying and description are summarized in Table 2.

Table 2. Characteristics and underlying principles

\begin{tabular}{ll}
\hline Characteristics & Underlying principles
\end{tabular}

1. The test-takers reveal expressive and integrative arguments either in meaningful connection, support or against, e.g. topis sentence (henceforth TS) and Supporting Sentences (henceforth SS) are well connected and are bounded with concluding sentences (CS).

2. The test-takers is directed by the logic where the flows of proposition go self-regulated learning, with the aid of the step-by-step phases. E.g. what to write is what the step directs.

3. The test-takers recall a chance to find feedbacks in non-test taking only. collaborating, It is not applicable in the real test. E.g. peer feedback and teacher feedback.

4. The test-takers think judgmentally and resourcefully while composing critical and creative each stage of the technique, e.g. the contents is fundamental and thinking, inventive not repetitive, e.g. when writing supporting details (henceforth SD)

5. The test-takers obtain the maximum standard which is proven by the reaching high standards good result of the designated criteria, e.g. The score is upper then 23 to of learning process. 30 of iBT or upper than 80 to 100 in classroom context.

6. Test-takers spend the given time with full production for both integrated effective and independent tasks, e.g. 25 minutes for integrated task, and 30 minutes for independent task.

7. Test-takers produce truthful composition for both integrated and accurate independent tasks. E.g. what is written is true based on the thesis statement (henceforth ThS), and supporting details or example (henceforth SD)

8. Test-takers produce the whole aspect as implied by the given topic in comprehensive good unity and coherence, e.g. a thesis statement (ThS) and concluding sentence (henceforth CS)

3.3 How the FBFRP technique is validated by the Tesmer (2013) Formative Evaluation?

\subsubsection{Pre-Stage: Self Evaluation}


The researcher reflected and analyzed the vivid result of essay writing papers submitted by the students who took essay class from the past five years. The number of papers; however, was taken purposively and with snow bowling approach of non-probability sampling. The result was taken into consideration as the basis foundation of me to compose a basic draft or so-called initial prototype one. He revisited this work and reviewed it critically. It was called checking obvious errors. He found some mistyped on the text. Accordingly, he revised it and made as a prototype one.

\subsubsection{First Stage : Expert Review and One to One}

The review by the expert indicated that the designed protype has minor issues to revise. First, it was suggested to use "concluding sentence" instead of a "topic sentence" in the body of paragraphs. Further, it was suggested to add point by point sentences and a clear conclusion. Finally, it was about coherence, and feedback. All of these suggestions are considered to revise the prototype. The full table of suggestion is attached in the appendix 1 .

Following the expert judgement was feedback from one-to-one of both male and female students. Both of them rated $96 \%$ and $93 \%$ of clarity, appeal, and obvious errors. However, none of them suggested any issues to revise since the reviewed prototype was a revised version from the expert judgment. The full review in the stage one-to-one is attached in the appendix-2 and 3 .

\subsubsection{Second Stage: Small Group Stage}

The small stage utilized mixed 26 students in the stage "user acceptance." All were requested to rate with scales; interesting, interesting enough and not interesting. This resulted that protypes was both interesting enough and interesting. The ten questions were rated interesting with $105(39.92 \%)$ points and interesting enough with $136(51.71 \%)$ points, and not interesting with $22(8.36 \%)$ points. Both ratings are positive. The full rating table is attached in appendix-4.

Then they rated "implementability" in two categories: "Yes or No." This resulted that protypes was "Yes with $264(82.24 \%)$ points and no with $57(17.75 \%)$ points. The statement "yes" indicated strong agreement on implementability. The full rating table is attached in appendix-5A.

In addition to the scale "Yes or No", they also rated qualitatively with small notes. The results showed that all notes tent to be positive with minor drawbacks to consider. Both quantitative and qualitative rating makes the review clearer and thus acceptable. The full review is attached in appendix-5B.

Furnishing the user acceptance and impelementability are organizational acceptance. This stage utilized 26 mixed students to rate the prototype. They were requested to use "Yes or No" statements. The result showed that they rated $217(83.14 \%)$ yes and $44(16.47 \%)$ no. This indicated that the level of organizational acceptance is strong by the raters. The full rating is attached in the appendix-6A.

Along with organizational acceptance with Yes or No is qualitative notes. They generally noted their concern based on their view as raters. They expressed many various concern in different level. However, the notes were constructive. The recap of notes is attached in the appendix-6B.

\subsubsection{Third Stage: Field Test}


The third stage of validation was field test. This stage was done in three targets: user acceptance, implementability and organization acceptance. All utilized 27 mixed students.

In the user acceptance, they rated $100(40.32 \%)$ points with interesting and $137(55.24 \%)$ with interesting enough and $11(4.43 \%)$ not interesting. Both made the strongly positive rating $95.24 \%$ against poor disagreement of $4.43 \%$.

Then they rated "implementability" in two categories: "Yes or No." This resulted that protypes was "Yes with $250(94.69 \%)$ points and no with $14(5.30 \%)$ points. The statement "yes" indicated strong agreement on implementability. The full rating table is attached in appendix-8A.

In addition to the scale "Yes or No", they also regarded qualitatively with small notes. The results showed that all notes tent to be positive with minor drawbacks to consider. Both quantitative and qualitative rating made the review clearer and thus acceptable. The full review is attached in appendix-8B.

Furnishing the user acceptance and impelementability are organization acceptance. This stage utilized 27 mixed students to rate the prototype. They were requested to use "Yes or No" statements. The result showed that they rated $220(81.4 \%)$ Yes and $50(18.51 \%)$ no. This indicated that the level of organizational acceptance is $81,4 \%$ of the raters. The full rating is attached in the appendix-9A.

\subsection{Discussion}

The current study has resulted a new product called "FBFRP Technique." It has been created under many consideration theoretical gaps [59]-[62] and practical gaps. The product is to solve many problems in computerized essay [3], [7] and amend the theories in writing essay [19], [44], [50]. This finding has contributed to the recent studies in the similar topic of essay [2], [46]-[49].

It is concluded that the product is designed as a technique [21], [23], [63]. With this technique a test taker may solve the discrepancy in the prior studies [5], [6], and harvest better outputs of iBT TOEFL Essay [1]. Briefly, the researcher has tried too many factorial gaps in the prior studies such as problems, theoretical gaps, and empirical gaps. It is also an answer to the need in digital age and the impact on learning [64].

The study also answers the second research questions and the results are learning principles and the process of validation. The product of the $\mathrm{R}$ and $\mathrm{D}$ is designed to easy the user when writing iBT TOEFL essays as a solution of the previous studies [12], [13], [65]. This study was also the perpetuation of the recent studies by the researcher [16], [66]. The study involves phases to follow and learning principles as the soul of the process.

In the stage of forward, a test taker may write a thesis statement, first topic sentence and a concluding sentence [19][50], second topic sentence and a concluding sentence and a conclusion in the last paragraph. All of these are under the learning principles "meaningful connection" [32][59]. These are skeleton of a full essay.

In the stage of back, a test taker is urged to revise the existing draft by writing a hook and general statement in the introductory paragraph [19]. This is followed by making some supporting sentences for each paragraph. The whole process is under the principle of selfregulated learning [33][34], logical, chronological [40] and critical [42][59]. These are the semiskin layers of an essay.

In the stage of forward, a test taker is directed to consolidate the introductory paragraph [19]. It is also to write more detail sentences under the supporting sentences with supporting 
details or examples. It is furnishing the conclusion by adding some details sentences [50]. The principles involve interconnected and comprehensive thoughts, and effective sentences [59]. These are skin layers of an essay.

In the stage of revising, a test taker is pushed to think of unity and coherence [19], [50]. The test taker revisits and edits the existing draft with correct punctuation. The goal is to make sentences be connected [23]. It is also to make sentences are united and have certain meaningful sense despite diverse in sentences. This process applies for the self-regulated learning because it was proven to be positive [35]-[37]. It is then followed by employing the principle of collaborating or cooperative [38] and open-minded [59]. These are the ideal essay product.

Finally, it is publishing stage where a test taker is pushed to make sure if the essay is fine to publish. The process involves minor revising [23], reading, editing [45], and proofing the essay until it looks fine to submit. The test taker thinks comprehensively and mastery learning leading to a portfolio [59]. These are the fixation of writing an essay to gain successful writing essay proficiency [43].

Completing the principles, a test taker is directed to furnish the iBT TOEFL essay by judging the computerized essay with three closing steps: effective, accurate and comprehensive to meet the accuracy [52] [53].

It is concluded that each step has an underlying principle that must be done chronologically. The process ranges from general comprehensive to specific and detail composition or from stamen, argument, and examples.

Finally, the study answers the last research question. The whole process took the model of Tessmer [57]. The process involved various ability and across genders of 20 male and 50 female students in addition to a professor and two male and female students. They were involved in the whole stages [67]

\subsubsection{Pre-Stage: Self Evaluation}

This stage was a basis foundation for the initial prototype. In this stage, the researcher himself who designed and revisited the result to find the errors. It was called checking obvious errors. Accordingly, he revised the errors and made the revised one as a prototype-one. The degree of acceptance was good which was highly acceptable [66].

\subsubsection{First Stage: Expert Review and One to One}

The next stage was review from an expert professor. It was found some errors to revise. However, the flaws were minor so that they did not change the prior model. Following this process was one-to-one of both male and female students. They rated $96 \%$ and $93 \%$ of clarity, appeal, and obvious errors. The protype-one was then revised. The degree of acceptance was excellent which was absolutely acceptable [14].

\subsubsection{Second Stage: Small Group Stage}

The small group rated the revised prototype form expert review and one-to-one. They rated "user acceptance" with 39.92\% interesting and 51.71\% interesting enough, and $8.36 \%$ not interesting. The degree of acceptance was excellent which meant absolutely acceptable. They rated "implementability" with $82.24 \%$ yes and $17.75 \%$ no. The degree of acceptance was excellent which meant absolutely acceptable [14]. They also rated qualitatively with small notes. They showed positive tendency with minor drawbacks to consider. Lastly, they rated on 
"organizational acceptance" with $83.14 \%$ yes and $16.47 \%$ ) no. This indicates that the level of acceptance was excellent which meant absolutely acceptable [14]. In addition, they generally noted their concern based on their view as raters. They advocated many various concern in different level but the notes were constructive.

\subsubsection{Third Stage: Field Test}

The last stage was field test of "user acceptance." In this stage they rated "user acceptance" with $40.32 \%$ interesting and 55.24\% interesting enough and $4.43 \%$ not interesting. This indicated strongly positive rating with $95.24 \%$ against the poor disagreement of $4.43 \%$. They rated "implementability" with $94.69 \%$ yes and $5.30 \%$ no. This indicated a strong agreement on implementability. They also regarded qualitatively with small notes but positive with minor drawbacks to consider. Lastly, the rated on "organizational acceptance with $81.4 \%$ yes and $18.51 \%$ no. This indicated a high level of organizational acceptance. The degree of user acceptance, implementability and organizational acceptance were excellent which meant absolutely acceptable [14].

The while validation process is excellent which means absolutely acceptable for the product to use in the actual test. However, a limited experimental study is needed [14]. This study has laid a novelty for any scholars and thus his contribution for the knowledge.

\section{Conclusion}

Referring to the research questions, and considering all aspects included and processes went through in this research, the researcher concludes that the Forward Back Forward Revising and Publishing (FBFRP) technique is believed to answer the test takers in that they can write the essay fast and accurate and thus harvesting good essay product.

The characteristics of CTL: meaningful connections, self-regulated learning, collaborating, critical and creative thinking, and high standards are inherent in this designed technique. In addition, effective, accurate and comprehensive are the fence. Thus, FBFRP Technique has answered at least the following characteristics: (1) meaningful connections are used in the stage of "forward", (2) Self-regulated is used in the whole procedure of FBFRP. (3) Collaborating is used in the stage of revising, peer revision and teacher revision. (4) Critical and creative thinking are used in the stage of second "forward" during the composing of supporting sentences (SS) and supporting details (SD). (5) Increasing the high standards of computerized essay and successful writing proficiency, and ideal writing product. (6) Effective, accurate and comprehensive as normative product of the essays for both integrated task and independent essay writing.

The process of validation has met the standard in that all rated or reviewed exceed the level of acceptance with excellent or called absolutely acceptable. This mean that the process of validation did not have any flaws to revise. The whole stage has contributed to the better development process until the last process of limited field test.

To wrap the finding, the created technique of FBFRP Technique is a new technique to promote a computerized-based essay test and is applicable in the iBT TOEFL test, and teaching purpose at university level. 


\section{References}

[1] ETS, "TOEFL iBT: Test and Score Data Summary 2019," 2019. [Online]. Available: www.ets.org/toefl.

[2] D. Turmudi, "Investigating the indonesian EFL students' argument in argumentative essay," Premise J. English Educ. Appl. Linguist., vol. 9, no. 2, pp. 251-276, 2020, doi: 10.24127/pj.v9i2.3079.

[3] R. Toba, W. N. Noor, and L. O. Sanu, "The Current Issues of Indonesian EFL Students' Writing Skills: Ability, Problem, and Reason in Writing Comparison and Contrast Essay," Din. Ilmu, vol. 9, no. 1, pp. 57-73, 2019, doi: 10.21093/di.v19i1.1506.

[4] L. Llosa and M. E. Malone, "Comparability of students' writing performance on TOEFL iBT and in required university writing courses," Lang. Test., vol. 36, no. 2, pp. 1-29, 2018, doi: $10.1177 / 0265532218763456$.

[5] M. Lister, "Trends in the Design of E-Learning and Online Learning," J. Online Learn. Teach., vol. 10, no. 4, pp. 671-680, 2014, [Online]. Available: http://ezproxy.auckland.ac.nz/login?url=http://search.ebscohost.com/login.aspx?direct=true \&db=eh $\mathrm{h} \& \mathrm{AN}=100728968 \&$ site $=$ ehost-live \&scope $=$ site.

[6] C. Zhang, X. Yan, and X. Liu, "The development of EFL writing instruction and research in China: An update from the International Conference on English Language Teaching," J. Second Lang. Writ., vol. 30, pp. 14-18, Dec. 2015, doi: 10.1016/j.jslw.2015.06.009.

[7] L. Llosa and M. E. Malone, "Student and instructor perceptions of writing tasks and performance on TOEFL iBT versus university writing courses," Assess. Writ., vol. 34, no. February, pp. 88-99, 2017, doi: 10.1016/j.asw.2017.09.004.

[8] A. M. Riazi, "Comparing writing performance in TOEFL-iBT and academic assignments: An exploration of textual features," Assess. Writ., vol. 28, pp. 15-27, 2016, doi: 10.1016/j.asw.2016.02.001.

[9] J. Smart, "Affordances of TOEFL writing tasks beyond university admissions," Assess. Writ., vol. 41, no. June, pp. 80-83, 2019, doi: 10.1016/j.asw.2019.06.006.

[10] J. Fleckenstein, S. Keller, M. Krüger, R. J. Tannenbaum, and O. Köller, "Linking TOEFL iBT® writing rubrics to CEFR levels: Cut scores and validity evidence from a standard setting study," Assess. Writ., vol. 43, no. July 2019, p. 100420, 2020, doi: 10.1016/j.asw.2019.100420.

[11] E. Y. J. Kim, "The TOEFL iBT writing: Korean students' perceptions of the TOEFL iBT writing test," Assess. Writ., vol. 33, pp. 1-11, 2017, doi: 10.1016/j.asw.2017.02.001.

[12] T. Sathya, "Developing an e-content module on the poem 'The Road Not Taken' - an experimental study," IJELR, vol. 3, no. 1, pp. 149-152, 2016.

[13] B. G. Wullur, "Developing an English Performance Test for incoming Indonesian college students," Indones. J. Appl. Linguist., vol. 1, no. 1, pp. 58-72, 2011, doi: 10.17509/ijal.v1i1.99.

[14] D. Turmudi and Y. Baihaqi, "Developing an English Essay materials for university students," in The 11 th FLA International Conference, 2019, pp. 17-30.

[15] D. Turmudi, “An Analysis on the Students' Trend in Writing Course," in THE THIRD UAD TEFL INTERNATIONAL CONFERENCE PROCEEDINGS " ELT Materials Development in Asia and Beyond: Directions, Issues, and Challenges ", 2014, pp. 181-195.

[16] D. Turmudi, "The influencing factors addressed in EFL essay writing class in Indonesia," Asian EFL J. Prof. Teach. Artic., no. 83, pp. 4-33, 2015, doi: 10.1007/s002489900087.

[17] A. Mangen, L. G. Anda, and G. H. Oxborough, "Handwritinng versus keyboard writing: Effecs on word recall," J. Writ. Res., vol. 7, no. 2, pp. 227-247, 2015, doi: 10.17239/jowr-2015.07.02.01.

[18] C. Palermo and M. M. Thomson, "Teacher implementation of Self-Regulated Strategy Development with an automated writing evaluation system: Effects on the argumentative writing performance of middle school students," Contemp. Educ. Psychol., vol. 54, no. July, pp. 255-270, Jul. 2018, doi: 10.1016/j.cedpsych.2018.07.002.

[19] A. Oshima, Alice and Hogue, Introduction to Academic Writing, 3rd ed. Plains, NY: Pearson Longman, 2007.

[20] C. N. Davidson and D. T. Goldberg, "Our Digital Age: implications for learning and its (online) institutions,” vol. 9, no. 3, pp. 249-266, 2012, doi: 10.2304/elea.2012.9.3.249. 
[21] D. Larsen-Freeman and M. Anderson, Techniques \& Principles in Language Teaching, Third. Oxford 0X2 6DP Oxford: OUP, 2011.

[22] T. S. Richard, J. C., \& Rodgers, Approaches and Methods in Language Teaching, 2nd ed. Cambridge, USA: Cambridge University Press., 2001.

[23] D. Brown and H. Lee, Teaching by Principles: An Interactive approach to Language Pedagogy, 4th ed. California, USA: Pearson Education, 2015.

[24] J. Harmer, The Practice of English Language Teaching. Essex: Pearson Education Limited, 2001.

[25] J. Harmer, “Thinking about Language Teaching: Selected Articles 1982-2011," ELT J., vol. 67, no. 2, pp. 250-253, 2013, doi: 10.1093/elt/cct002.

[26] L. Y. Chang, "TESOL teachers 'divergent reflective thinking on what makes a language teacher 'good ,"," Soc. Sci. Hunanities, vol. 3, no. 2, pp. 413-419, 2012.

[27] I. Satriani, E. Emilia, and H. Gunawan, "Contextual teaching and learning approach to teaching writing,” Indones. J. Appl. Linguist., vol. 2, no. 1, p. 10, Jul. 2012, doi: 10.17509/ijal.v2i1.70.

[28] C. C. Hudson and V. R. Whisler, "Contextual teaching and learning for practitioners," in IMSCI 2007 - International Multi-Conference on Society, Cybernetics and Informatics, Proceedings, 2007, vol. 2, pp. 228-232.

[29] S. Sears, Introduction to Contextual Teaching and Learning. Indiana: the Phi Delta Kappa Educational Foundation, 2003.

[30] E. Hinkel, Teaching Academic ESL Writing: practical technique in vocabulary and grammar. New Jersey and London: LAWRENCE ERLBAUM ASSOCIATES, PUBLISHER, 2004.

[31] C. C. Hudson and V. R. Whisler, "Contextual Teaching and Learning for Practitioners," Syst. Cybern. Informatics, vol. Vol. 6, no. 4, pp. 54-58, 2013, [Online]. Available: http://www.iiisci.org/journal/cv\$/sci/pdfs/e668ps.pdf.

[32] L. Wu, V. T. Betts, S. Jacob, R. Nollan, and T. Norris, "Making meaningful connections: Evaluating an embedded librarian pilot project to improve nursing scholarly writing," J. Med. Libr. Assoc., vol. 101, no. 4, pp. 323-326, 2013, doi: 10.3163/1536-5050.101.4.016.

[33] R. Baggetun and B. Wasson, "Self-regulated learning and open writing," Eur. J. Educ., vol. 41, no. 3-4, pp. 453-472, 2006, doi: 10.1111/j.1465-3435.2006.00276.x.

[34] M. Nückles, S. Hübner, and A. Renkl, "Enhancing self-regulated learning by writing learning protocols," Learn. Instr., vol. 19, no. 3, pp. 259-271, 2009, doi: 10.1016/j.learninstruc.2008.05.002.

[35] D. C. Moos and A. Ringdal, "Self-Regulated Learning in the Classroom : A Literature Review on the Teacher's Role," Educ. Res. Int., vol. 2012, p. 15, 2012, doi: 10.1155/2012/423284.

[36] S. Zumbrunn, "Encourage Self Regulated Learning in The Classroom," Metrop. Educ. Res. Consort., pp. 1-28, 2011, [Online]. Available: http://scholarscompass.vcu.edu/merc_pubs/18.

[37] A. R. Artino and K. D. Jones, "Exploring the complex relations between achievement emotions and self-regulated learning behaviors in online learning," Internet High. Educ., vol. 15, no. 3, pp. 170175, 2012, doi: 10.1016/j.iheduc.2012.01.006.

[38] N. Ibrahim et al., "The Importance of Implementing Collaborative Learning in the English as a Second Language (ESL) Classroom in Malaysia," Procedia Econ. Financ., vol. 31, no. 15, pp. 346353, 2015, doi: 10.1016/s2212-5671(15)01208-3.

[39] S. Lindblom-ylänne and H. Pihlajamäki, "Can a collaborative network environment enhance essaywriting processes?,” Br. J. Educ. Technol., vol. 34, no. 1, pp. 17-30, 2003.

[40] K. C. Tsai, "Being a Critical and Creative Thinker: A Balanced Thinking Mode.," Asian J. Humanit. Soc. Sci., vol. 1, no. 2, pp. 1-8, 2013, [Online]. Available: www.ajhs.org.

[41] M. Baker, R. Rudd, and C. Pomeroy, "Relationships between Critical and Creative Thinking," J. South. Agric. Educ. Res., vol. 51, no. 1, pp. 173-188, 2001.

[42] J. Beaumont, “A Sequence of Critical Thinking Tasks," TESOL J., vol. 1, no. 4, pp. 427-448, Dec. 2010, doi: 10.5054/tj.2010.234763.

[43] V. Evans, Successful Writing Proficiency, New Editio. Express Publishing ., 2000.

[44] K. Grenville, Writing from Start to Finish: A Six-Step Guide. Allen\&Unwin, 2001.

[45] G. Sundem, Improving students' Writing Skills, Reprinted. California, USA: Shell Education, 2006. 
[46] P. Stapleton and Y. (Amy) Wu, "Assessing the quality of arguments in students' persuasive writing: A case study analyzing the relationship between surface structure and substance," J. English Acad. Purp., vol. 17, pp. 12-23, 2015, doi: 10.1016/j.jeap.2014.11.006.

[47] M. Liu and G. Braine, "Cohesive features in argumentative writing produced by Chinese undergraduates," System, vol. 33, pp. 623-636, 2005, doi: 10.1016/j.system.2005.02.002.

[48] V. Ho and C. Li, "The use of metadiscourse and persuasion: An analysis of fi rst year university students ' timed argumentative essays," J. English Acad. Purp., vol. 33, pp. 53-68, 2018, doi: 10.1016/j.jeap.2018.02.001.

[49] F. H. van Eemeren, P. Houtlosser, and A. F. S. Henkemans, "Dialectical profiles and indicators of argumentative moves .pdf," J. Pragmat., vol. 40, pp. 475-493, 2008.

[50] A. Hogue, First Steps in Academic Writing, 2 nd. Plains, NY: PEARSON Longman, 2008.

[51] G. Broughton, C. Brumfit, R. Flavell, P. Hill, and A. Pincas, Teaching English as Foreign Language, 2nd ed., vol. 7, no. 2. London and New York: Routledge, 2003.

[52] S. Bailey, Academic Writing. 2006.

[53] S. Bailey, Academic Writing: A Handbook for International Students, Third edition, 3rd ed. London and New York: Routledge:Taylor \& Francis e-Library, 2011.

[54] D. Turmudi, "Rethinking Academic Essay Writing : Selected Genres in Comparison," Premise J., vol. 6, no. 2, pp. 119-138, 2017, doi: 10.24127/pj.v6i2.1052.

[55] B. Kumaravadivelu, "Postmethod," TESL-EJ, vol. 11, no. 3, pp. 1-3, 2007.

[56] M. D. Gall, J. P. Gall, and W. R. Borg, Educational Research, Seventh. Boston, New York,San Francisco, Mexico City, Montreal, Toronto, London, Madrid,Munich, Paris, Hongkong, Singapore, Tokyo, Cape Town, Sydney: Pearson Education, Inc., 2003.

[57] M. Tessmer, Planning and conducting formative evaluations, 1st ed. Routledge: Routledge, 2013.

[58] M. B. Miles, M. a Huberman, J. Saldana, A. M. Huberman, and J. Saldana, Qualitative Data Analysis: A Methods Sourcebook, 3rd ed. SAGE Publications, 2014.

[59] E. B. Johnson, Contextual teaching and learning: what it is and why it is here to stay. California: Corwin Press, 2002.

[60] D. Kaufman, "14 Constructivist Issues in Language Learning and Teaching," Annu. Rev. Appl. Linguist., vol. 24, pp. 303-319, 2004, doi: 10.1017/s0267190504000121.

[61] V. Kapur, "Understanding constructivism in the second language learning context," Sch. Res. J. Humanit. Sci. English Lang., vol. 5, no. 25, pp. 7061-7080, 2017.

[62] M. Aljohani, "Principles of 'Constructivism' in Foreign Language Teaching," J. Lit. Art Stud., vol. 7, no. 1, pp. 97-107, 2017, doi: 10.17265/2159-5836/2017.01.013.

[63] J. C. Richards, "The Changing Face of Language Learning: Learning Beyond the Classroom," RELC J., vol. 46, no. 1, pp. 5-22, Apr. 2015, doi: 10.1177/0033688214561621.

[64] C. Williams and S. Beam, "Technology and writing: Review of research," Comput. Educ., vol. 128, pp. 227-242, Jan. 2019, doi: 10.1016/j.compedu.2018.09.024.

[65] J. A. Foley, "Developing academic writing in a business-oriented university," Indones. J. Appl. Linguist., vol. 2, no. 2, pp. 168-186, 2013, doi: 10.17509/ijal.v2i2.163.

[66] D. Turmudi and Y. Baihaqi, "Developing Essay Materials of English for University Students," in The 11 th FLA International Conference, 2019, pp. 17-30.

[67] A. Huhta, R. Alanen, M. Tarnanen, M. Martin, and T. Hirvelä, "Assessing learners' writing skills in a SLA study: Validating the rating process across tasks, scales and languages," Lang. Test., vol. 31, no. 3, pp. 307-328, 2014, doi: 10.1177/0265532214526176. 